\title{
Emotional Intelligence and the Ability to Make a Decision to the Scholastic Administrative Leaderships "Comparative Study"
}

Ahmed Kamal Nassary*, Ezz El-Din Hussein Solayman**, Majed Mohammed Saeed Ali Azzazi***

\section{The Introduction and the Problem of the} Research:

$\mathrm{T}$ he human behavior comes from the interaction between the man who has certain features, and keeps a determined concepts thoughts and opinions for himself concerning a lot of objects, and the situation that forms the surrounding a circumstances of a person. This situation reveals/ forms the available chances for the person and the boundaries which he has to deal with and the trial to use these chances to achieve his wishes and reach his targets, within the boundaries in the situation.

A lot of studies have been made in the field of the emotional intelligence and the ability of taking a decision, such as study of New Sam and Kato (2000), Fawkia Rady (2001), Martha and George (2001), Stotlemer (2002), Mohamed Mahmoud Nageeb (2002), Barker (2004), Witsweesky et al. (2004) Ghada Al Gendy (2006), Souhad Almouly (2008), and these studies have shown the importance of having the making decision skills and the criteria of judging the decision and the importance of participating in making the decisions.

Through the readings of the researchers and what mentioned previous, and the studies that done before, they noticed that although the variations that exist in the previous studies is the field of emotional intelligence and the ability of making a decision, and the studies in the sport field, the researchers didn't find that in their

\footnotetext{
* Professor, Faculty of Physical Education, South Valley University, Egypt.

** Lecturer, Faculty of Physical Education for Boys, Zagazig University, Egypt.

*** Lecturer, Faculty of Physical Education, Banha University, Egypt.
}

knowledge. Any one who may use it to develop the scholastic management and clarify the vision to those who make the decisions and responsible for the management, therefore the idea of this research comes to recognize the emotional intelligence and the ability of making the decision for the scholastic administrative leaderships.

\section{The Importance of the Research and the Use of It:}

- The emotional intelligence is considered the key of success in the career life compared to the academic intelligence which is the key of success in the educational and academic life. This is what Goleman confirms, saying that the academic intelligence has a small role in dealing with the emotional life for any one compared to the emotional intelligence.

- Recognize the relationship between the emotional intelligence and the ability of taking a decision for the scholastic administrative leaderships.

- its dealing with more than one element each one has his own importance like the emotional intelligence and the ability of making a decision, also its dealing with one of the most important categories that needs making decision and using the different manners that work on the quality of the decision in the scholastic management.

- Using the results of this research in contributing in making the development program for the scholastic administrative leaderships. 


\section{The Research Objectives:}

1. The relationship between the emotional intelligence and the ability of taking the decision for the scholastic administrative leaderships.

2. Identify the impact of high emotional intelligence in decision-making

3. Identify the impact of low emotional intelligence in decision-making

4. The differences between those with high emotional intelligence and with low emotional intelligence in the ability of making the decision.

5. The differences between males and females in the scholastic administrative leaderships in emotional intelligence and the ability of making a decision.

\section{The Hypotheses of the Research:}

In the light of the research's targets, the researchers suppose that:

1. There is a statistically functional correlative relationship between the emotional intelligence and the ability of morning a decision for the scholastic administrative leaderships.

2. There are a statistically functional differences in the emotional intelligence between the scholastic administrative leadership.

3. There are statistically functional differences between those with high emotional intelligence and those with low emotional intelligence in the ability of making the decision.

4. There are statistically functional difference between males and females in the scholastic administrative leaderships in the emotional intelligence and the ability of making the decision.

\section{The Research Terminology:}

\section{Emotional intelligence:}

Bar-own defines the emotional intelligence as a collection of the emotional, personal and social abilities, which enable the person to adjust the surrounded difficulties.

\section{The ability of making the decision:}

It's a complex mental activity aims at when one responds to a certain situation, he needs to choose the best included behaviors in such situation as a solution, and this happens through the mental reorganizing of the information for the one. (13:17)

\section{The scholastic administrative leaderships:}

We meant by it in the research he managers and the head masters for the preparatory schools and the employees in the educational managements in Zagazig and Kenna governorate.

\section{The Research Procedures:}

\section{The research methodology:}

\section{The researcher:}

Used the descriptive style due to the nature of the research.

\section{The research samples:}

The research's samples contain the managers of the preparatory schools in Zagazig and Kenna and the management that follow them in Zagazig and Kenna, they are about (450) person almost, and the samples which were chosen were about (150) person, they represent about $33 \%$ from the total.

\section{They have the following conditions:}

- They should obtain a high education degree.

- They should spend more than 2 years in the career.

- They should live in the city they worked

\section{The research tools:}

This research has the following tools:

1. The emotional intelligence measurement (Farouk Al Said Outman - Mohamed Abdel Sammee Rezk).

2. The ability of making the decision measurement (the researchers).

\section{The emotional intelligence measurement:}

- The measurement includes in its initial form (64): phrases using five responses measurements (always - often - sometimes seldom - never). The measurement was introduced, in its initial form - to number of the 
teaching staff, factually of education, Mansoura University, the modifications lead to make modifications in the formulation of the measurement parts, this measurement was applied to a sample which was about 42 males and females students, third year, Faculty of education, Al Mansoura University. The Purpose of this was to confirm the clarity of the measurement and the clear understanding of the instructions, the elementary analysis was used and these steps lead to eliminate (6) phrases that leads the phrases to be (58) phrases in their final form.

\section{The effectiveness of the test:}

The effectiveness of the test was found through calculating the differences between Swat the highest and Swat the lowest on a sample about (136) males and females students, third year, faculty of education. The range of the value (T) was between 1.92, 4.64 and the whole function value was about 0.01 .

To find the scientific coefficient for the measurement of this research, the researchers found the self effectiveness of the stability coefficient.

The following table No (1) illustrates that:

Table (1)

Self effectiveness for the emotional intelligence measurement

\begin{tabular}{|c|c|c|}
\hline The dimensions of self image & Stability coefficient & Self effectiveness coefficient \\
\hline Emotional management & 0.561 & 0.749 \\
\hline Empathy & 0.711 & 0.843 \\
\hline Emotional organizing & 0.623 & 0.789 \\
\hline Emotional knowledge & 0.467 & 0.683 \\
\hline Social communication & 0.583 & 0.764 \\
\hline
\end{tabular}

\section{The Stability of the Measurement:}

The stability for the measure was found using Alfa Kronbakh's method, and the stability factors ranged between 0.49 and 0.81 and the stability values were functional at the level 0.01 .

To find the stability of this research, the researchers found the stability by applying the measure on the regulatory sample (30) twenty specialists working in the sports field in the directorate of youth and sports in Zagazig and Kenne, then they reapplied the measure - after two weeks, on the same sample and under the same conditions. Then the correlation coefficient was measured between the two applications. Table (2) illustrates the results.

Table (2)

The stability factor for the emotional intelligence measure $N=20$

\begin{tabular}{|c|c|c|c|c|c|}
\hline \multirow{2}{*}{ Self image dimensions } & \multicolumn{2}{|c|}{ First application } & \multicolumn{2}{c|}{ Second application } & \multirow{2}{*}{$\begin{array}{c}\text { Correlation } \\
\text { coefficient }\end{array}$} \\
\cline { 2 - 5 } & $\mathbf{M}$ & $\mathbf{P}$ & $\mathbf{M}$ & $\mathbf{P}$ & 0.561 \\
\hline Emotional management & 11.26 & 4.26 & 11.02 & 4.22 & 0.711 \\
\hline Empathy & 8.57 & 3.57 & 7.88 & 3.88 & 0.623 \\
\hline Emotional organizing & 9.33 & 4.33 & 8.96 & 4.12 & 0.467 \\
\hline Emotional knowledge & 7.11 & 3.41 & 7.01 & 3.68 & 0.583 \\
\hline Social communication & 7.09 & 3.17 & 7.21 & 3.11 & 0 \\
\hline
\end{tabular}

(R) value at level $(0.05)=0.211$ 
The previous table illustrates that:

- There is a functional relationship between the first and second application concerning the emotional intelligence measure and this means the stability of the measure.

- The ability of making the decision (the researchers) this measure, the researchers made a lot of steps through which they could reach an initial image/ form which was applied on a group of administrative leaderships in Kenna and Zagazig from the society of the research and outside the original sample.

\section{Making the Measure Steps:}

- The researchers made a comprehensive survey study for the previous studies and researches that work on making a decision, an this study reveals that all the studies they found and collected didn't include any researchers in the sports field and the education field - in their knowledge - also they have looked at the scientific references and the tests that were done in this field.

- The specialists in the education field and psychology and sports education were asked their opinion on the most important parts that influence making a decision for the employees in the scholastic administration.

- A group of teachers from different educational levels were asked their opinion through an open question, its target is recognizing the most important decisions that the leaders of the administration in schools made and how honest they are and how they link the reality.

- The teachers from different educational levels were asked their opinion on the most important decisions and how qualified they are and how they fulfill their targets, and what are the most important stills that the decision maker needs.

- The main axes were determined, on which the measure build, they were (g) axes that represent the different aspects for taking the decision, they were:

1. The personal characteristics for the decision maker
2. The organizational culture

3. Taking the decision criteria

4. the factors that influence making the decision.

5. The organizational atmosphere.

6 . The effectiveness of the organization and the measure criteria.

7. The way of taking the decision.

8. The factors that influence the organizational manner.

9. The skills of making the decision.

- The axes were introduced to specialists in the educational, psychological and sports educational fields. They were (9) nine judges to judge the fitness of the axes the measure represents, the agreement percentage was between $72,87 \%$ between the judges. In the light of this some of the axes were deleted and some of them were reformulated. As a result the number of the axes is (7) seven axes representing the main axes as follow:

1. The characteristics and the features of the body.

2. The organization culture

3. The organizational atmosphere

4. The organization manner

5 . The way of making the decision

6. The factors that influence making the decision

7. The skills for making the decision

- The researchers formulated some phrases for each axis that represent the measure, they were (73) seventy three phrases.

- The measure was introduced to some judges to confirm. The fitness of the phrases for the dimensions that they represent, some phrases were eliminated because of repetition or to modificate the formulation of some of them, the agreement percentage between the judges concerning the phrases is $76 \%$ from (9) judges.

- The measure was formulated in its final form and the number of the axes was (7) seven axes measuring (64) sixty four phrase. 
- The researchers used "Lekert" manner to fix the measure through putting the whole phrases on a list contains 3 scalable answers, the researchers didn't defined a certain time to answer the measure, the degrees were estimated by putting them on one link as follow:

\begin{tabular}{|c|c|c|}
\hline Agree & Disagree & $\begin{array}{c}\text { To some } \\
\text { extent }\end{array}$ \\
\hline 3 & 2 & 1 \\
\hline
\end{tabular}

- The degree of the measure represents the total degrees that the leader has to answer all the phrases, so the higher degree becomes 192) degree, and the lowest degree becomes (64) degree, and to confirm the validity of the measure, it was applied on a random sample of preparatory schools' headmasters in Zagazig and Kenna about (30) thirty one.

\section{The Coefficients for the Scientific Measurement:}

\section{First: Honesty}

The researchers calculated honesty through:

1. The honesty of the content

2. The honesty of internal consistency

\section{(1) The honesty of the content:}

The researchers introduced the measure to a group of professional judges in education and psychology and sports education, to judge the fitness of the axes of the measure, also the fitness of the phrases for each axis of the axes, some of phrases were eliminated for their repetition or their in appropriation or to reformulate some of them to express the measure effectively, the number of axes is seven, the number of the phrases is (73) seventy three and tables (3 and 4) illustrate the agreement percentage of the judges concerning the axes and the phrases. 
Table (3)

The judges agreement percentage about the axes

\begin{tabular}{|c|c|}
\hline The axes & Agreement percentage \\
\hline The characteristics and the features of the body & $86 \%$ \\
\hline The organizational culture & $91 \%$ \\
\hline The organizational atmosphere & $93 \%$ \\
\hline The organizational manner & $89 \%$ \\
\hline The way of making the decision & $94 \%$ \\
\hline The elements that affect making the decision & $92 \%$ \\
\hline Taking the decision skills & $93 \%$ \\
\hline
\end{tabular}

Table (4)

The judges agreement percentage about the phrases

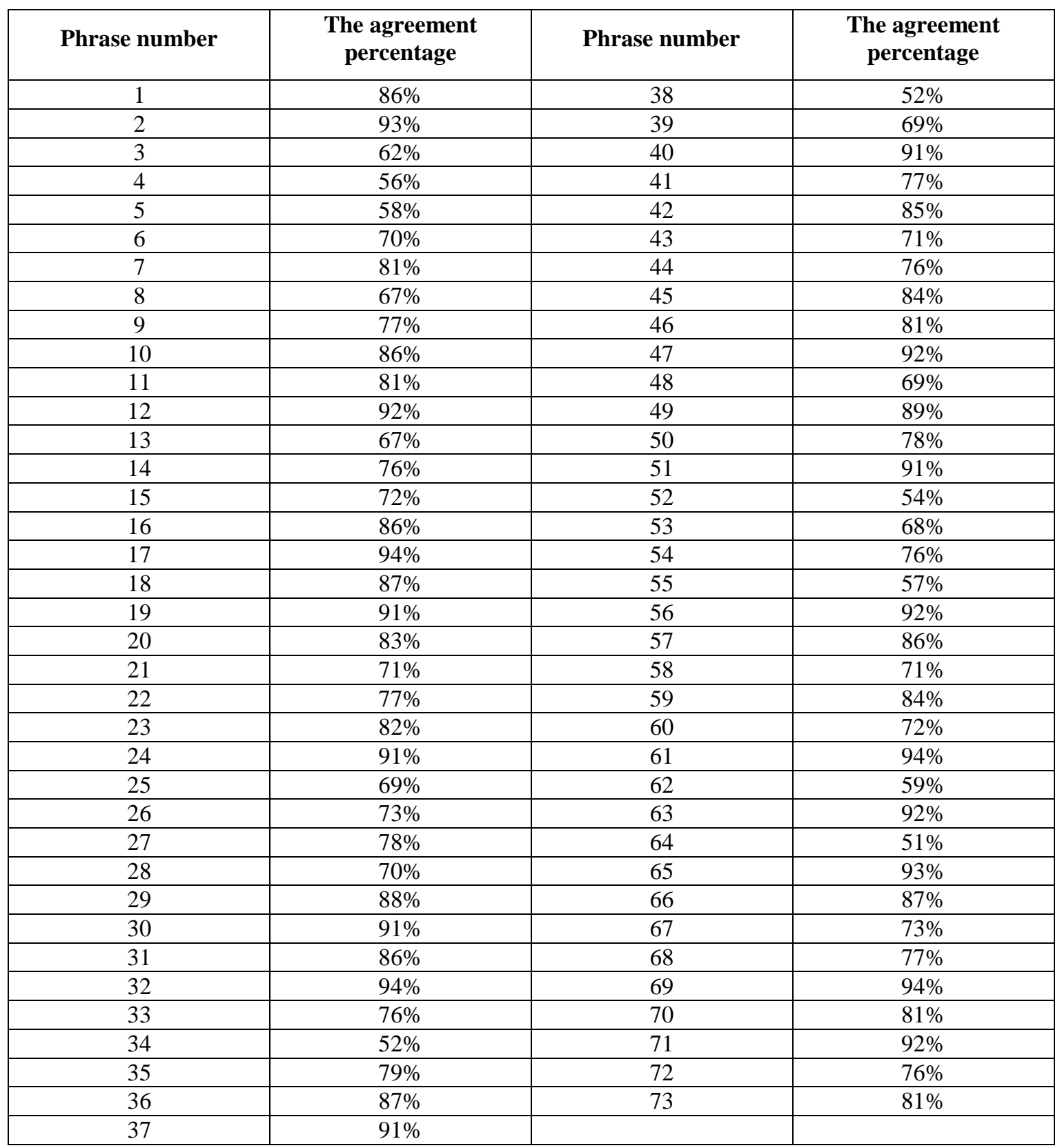


(2) The honesty of the internal consistency:

The researchers found the internal consistency of the measure between the total degrees of each axis, and the total degree of the measure and between the degrees of each phrase and the total degree of the measure. Table $(5,6)$ illustrate that

Table (5)

The correlation coefficient between the total degrees of each axis and the total degree of the measure

\begin{tabular}{|c|c|}
\hline The axes & The correlation coefficient \\
\hline The characteristics and features of the body & $86 \%$ \\
\hline The organizational culture & $91 \%$ \\
\hline The organizational climate (atmosphere) & $93 \%$ \\
\hline The organizational manner & $89 \%$ \\
\hline The way of making the decision & $94 \%$ \\
\hline The influences that affect making the decision & $92 \%$ \\
\hline The skills of making the decision & $93 \%$ \\
\hline
\end{tabular}

The tabular value $(R)$ : at the level of $(0.05=0.21)$

From the previous table we find out that the ranged between $(0.894),(0.941)$ and these are correlation coefficient between the total degrees statistically functional correlation coefficients, of each axes and the total degree of the measure and this means the honesty of the measure.

Table (6)

The correlation coefficients between the degree of each phrase and the total degree of the measure $N=20$

\begin{tabular}{|c|c|c|c|c|c|c|c|}
\hline $\begin{array}{c}\text { Phrase } \\
\text { number }\end{array}$ & $\begin{array}{c}\text { Correlation } \\
\text { coefficient }\end{array}$ & $\begin{array}{c}\text { Phrase } \\
\text { number }\end{array}$ & $\begin{array}{c}\text { Correlation } \\
\text { coefficient }\end{array}$ & $\begin{array}{c}\text { Phrase } \\
\text { number }\end{array}$ & $\begin{array}{c}\text { Correlation } \\
\text { coefficient }\end{array}$ & $\begin{array}{c}\text { Phrase } \\
\text { number }\end{array}$ & $\begin{array}{c}\text { Correlation } \\
\text { coefficient }\end{array}$ \\
\hline 1 & 0.871 & 20 & 0.769 & 39 & 0.873 & 58 & 0.669 \\
\hline 2 & 0.637 & 21 & 0.893 & 40 & 0.738 & 59 & 0.783 \\
\hline 3 & 0.924 & 22 & 0.741 & 41 & 0.853 & 60 & 0.911 \\
\hline 4 & 0.229 & 23 & 0.793 & 42 & 0.784 & 61 & 0.835 \\
\hline 5 & 0.279 & 24 & 0.764 & 43 & 0.714 & 62 & 0.264 \\
\hline 6 & 0.658 & 25 & 0.897 & 44 & 0.916 & 63 & 0.917 \\
\hline 7 & 0.742 & 26 & 0.865 & 45 & 0.697 & 64 & 0.297 \\
\hline 8 & 0.867 & 27 & 0.824 & 46 & 0.846 & 65 & 0.864 \\
\hline 9 & 0.658 & 28 & 0.931 & 47 & 0.717 & 66 & 0.771 \\
\hline 10 & 0.931 & 29 & 0.635 & 48 & 0.658 & 67 & 0.685 \\
\hline 11 & 0.764 & 30 & 0.897 & 49 & 0.865 & 68 & 0.692 \\
\hline 12 & 0.873 & 31 & 0.674 & 50 & 0.879 & 69 & 0.718 \\
\hline 13 & 0.856 & 32 & 0.637 & 51 & 0.746 & 70 & 0.763 \\
\hline 14 & 0.674 & 33 & 0.911 & 52 & 0.623 & 71 & 0.746 \\
\hline 15 & 0.862 & 34 & 0.266 & 53 & 0.922 & 72 & 0.922 \\
\hline 16 & 0.887 & 35 & 0.734 & 54 & 0.667 & 73 & $81 \%$ \\
\hline 17 & 0.746 & 36 & 0.682 & 55 & 0.243 & & \\
\hline 18 & 0.875 & 37 & 0.943 & 56 & 0.852 & & \\
\hline 19 & 0.748 & 38 & 0.266 & 57 & 0.934 & & \\
\hline
\end{tabular}

The tabular value of $\AA$ at the level $(0.052)=0.211$ 


\section{Second: Stability}

To calculate the stability, the researcher, used the following ways:

1. The way of reapplying the test

2. The mid term retail

(1) The way of reapplying the test:

Table (7)

The correlation coefficient between the two applications the first and the second to measure the ability to make the decision in the light of the style of the whole quality $N=20$

\begin{tabular}{|c|c|c|c|c|}
\hline \multicolumn{2}{|c|}{ First application } & \multicolumn{2}{|c|}{ Second application } & \multirow{2}{*}{$\begin{array}{c}\text { The correlation } \\
\text { coefficient }\end{array}$} \\
\hline $\mathbf{M}$ & $\mathbf{P}$ & $\mathbf{M}$ & $\mathbf{P}$ & \\
\hline 164 & 12.33 & 171 & 12.48 & 0.96 \\
\hline
\end{tabular}

The tabular value $(R)$ at the level $(0.05)=0.211$

From the previous table (7) we find out that there is statistically functional correlation between the first and second application to measure the ability of making the decision

(2) The way of midterm retail:

The researchers have applied the measure on a sample of (20) twenty leaderships in schools in Zagazig and Kenna governorates and away from the original samples the test was divided into take equal parts, the single phrases versus double phrases, the correlation coefficient was calculated between them, table 8 illustrates that.

Table (8)

The correlation coefficient between single phrases and double phrases to measure the ability taking the decision in the light of the style of the total quality $N=20$

\begin{tabular}{|c|c|c|c|c|c|}
\hline \multicolumn{2}{|c|}{ Single phrases } & \multicolumn{2}{c|}{ Double phrases } & \multirow{2}{*}{$\begin{array}{c}\text { The } \\
\text { correlation } \\
\text { coefficient }\end{array}$} & $\begin{array}{c}\text { The stability } \\
\text { coefficient }\end{array}$ \\
\hline 82 & $\mathbf{P}$ & $\mathbf{M}$ & $\mathbf{P}$ & 0.95 & 0.97 \\
\hline
\end{tabular}

The tabular value $(R)$ at the level $(0.05)=0.211$

From the previous table (8) we find out that the stability coefficient of measure is high and this reveals the stability of the measure.

\section{The Results and Their Explanation / Interpretation and Discussion:}

\section{The Results:}

The researcher will expose the results in the following arrangement:

1. The relationship between the emotional intelligence and the ability of making the decision to the scholastic administrative leaderships
2. The differences in the emotional intelligence between the scholastic administrative leaderships

3. The differences in the ability of taking the decision between the scholastic administrative leaderships

4. The differences between those of high emotional intelligence and low emotional intelligence concerning the ability of making the decision

First: The relationship between the emotional intelligence and the ability of making the decision to the scholastic administrative leaderships 
Table (9)

The correlation coefficient between the emotional intelligence and the ability of making the decision to the scholastic administrative leaderships $N=150$

\begin{tabular}{|c|c|c|c|c|}
\hline \multicolumn{2}{|c|}{ The emotional intelligence } & \multicolumn{2}{|c|}{ The ability of making the decision } & \multirow{2}{*}{$\begin{array}{c}\text { The correlation } \\
\text { coefficient }\end{array}$} \\
\hline $\mathbf{M}$ & $\mathbf{\pm}$ & $\mathbf{M}$ & $\mathbf{P}$ & 0.578 \\
\hline 198.7 & 5.34 & 174.28 & 8.22 & \multirow{2}{*}{} \\
\hline
\end{tabular}

The tabular value $(R)$ at the level $(0.05)=0.159$

From the previous table (9) we find out that there is a correlation between the emotional intelligence and the ability of the king a decision to the scholastic administrative leaderships.
Second: the differences in the emotional intelligence between the scholastic administrative leaderships

Table (10)

The differences in the emotional intelligence between the scholastic administrative leaderships $\quad N=150$

\begin{tabular}{|c|c|c|c|c|c|c|c|}
\hline \multirow{2}{*}{ Statement } & \multicolumn{2}{|c|}{ Kenna } & \multicolumn{2}{|c|}{ Zagazig } & \multirow{2}{*}{$\begin{array}{c}\text { The } \\
\text { average } \\
\text { (T) }\end{array}$} & \multirow{2}{*}{$\begin{array}{c}\text { The value of } \\
\text { (T) the } \\
\text { calculated }\end{array}$} & \multirow{2}{*}{$\begin{array}{c}\text { The } \\
\text { functiona } \\
\text { level }\end{array}$} \\
\hline & $\mathbf{M}$ & $\mathbf{P}$ & $\mathbf{M}$ & $\mathbf{P}$ & & & \\
\hline $\begin{array}{l}\text { Emotional } \\
\text { intelligence }\end{array}$ & 188.77 & 6.52 & 156.8 & 5.82 & 7.71 & 14.02 & functional \\
\hline
\end{tabular}

The tabular value $(T)$ at the level $(0.05)=1.59$

From the previous table (10) we find out that there is a statistical functional differences between the scholastic administrative leaderships in Kenna and Zagazig of emotional intelligence.
Third: The differences in the ability of making the decision between the scholastic administrative leaderships

Table (11)

The differences in the ability of making the decision between the scholastic administrative leaderships $\quad N=150$

\begin{tabular}{|c|c|c|c|c|c|c|c|}
\hline \multirow{2}{*}{ Statement } & \multicolumn{2}{|c|}{ Kenna } & \multicolumn{2}{|c|}{ Zagazig } & \multirow{2}{*}{$\begin{array}{c}\text { The } \\
\text { average } \\
(\mathbf{T})\end{array}$} & \multirow{2}{*}{$\begin{array}{c}\text { The value of } \\
\text { (T) the } \\
\text { calculated }\end{array}$} & \multirow{2}{*}{$\begin{array}{c}\text { The } \\
\text { functional } \\
\text { level }\end{array}$} \\
\hline & $\mathbf{M}$ & $\mathbf{P}$ & $\mathbf{M}$ & $\mathbf{P}$ & & & \\
\hline $\begin{array}{c}\text { The ability of } \\
\text { making a } \\
\text { decision }\end{array}$ & 170 & 11.23 & 174 & 11.05 & -4 & 2.07 & functional \\
\hline
\end{tabular}

The tabular value $(T)$ at the level $(0.05)=1.59$

From the previous table (11) we find out that there are statistical functional differences between the scholastic administrative leaderships in Zagazig and Kenna concerning the ability of making a decision.
Fourth: The differences between those with high and low emotional intelligence at their ability of making a decision between the scholastic administrative leaderships $\mathrm{N}=150$ 
Table (12)

The differences in the emotional intelligence between the scholastic administrative leaderships $\quad N=150$

\begin{tabular}{|c|c|c|c|c|c|c|c|}
\hline \multirow[t]{2}{*}{ Statement } & \multicolumn{2}{|c|}{$\begin{array}{l}\text { People with of } \\
\text { high emotional } \\
\text { intelligence } \\
\mathrm{N}=86\end{array}$} & \multicolumn{2}{|c|}{$\begin{array}{c}\text { People with low } \\
\text { emotional } \\
\text { intelligence } \\
N=64\end{array}$} & \multirow[t]{2}{*}{$\begin{array}{c}\text { The } \\
\text { average }\end{array}$} & \multirow[t]{2}{*}{$\begin{array}{c}\text { The value of } \\
\text { (T) the } \\
\text { calculated }\end{array}$} & \multirow[t]{2}{*}{$\begin{array}{c}\text { Functional } \\
\text { level }\end{array}$} \\
\hline & $\mathbf{M}$ & $\mathbf{P}$ & $\mathbf{M}$ & $\mathbf{P}$ & & & \\
\hline $\begin{array}{c}\text { The ability of } \\
\text { making a } \\
\text { decision }\end{array}$ & 186.11 & 9.54 & 171.32 & 8.46 & 14.49 & 1.33 & In functional \\
\hline
\end{tabular}

The tabular value $(T)$ at the level $(0.05)=1.59$

From the previous table (12) there are statistical infuntional differences between those with high and low emotional intelligence of the scholastic administrative leaderships in Kenna and Zagazig concerning the ability of making a decision
Fifth: The differences between males and females of the scholastic administrative leaderships concerning the emotional intelligence and the ability of making a decision.

Table (13)

The differences between those with high and low emotional intelligence at their ability of making the decision among the scholastic administrative leaderships $\quad N=150$

\begin{tabular}{|c|c|c|c|c|c|c|c|}
\hline \multirow[t]{2}{*}{ Statement } & \multicolumn{2}{|c|}{$\begin{array}{c}\text { Males } \\
N=67\end{array}$} & \multicolumn{2}{|c|}{$\begin{array}{c}\text { Females } \\
\mathbf{N}=\mathbf{8 3}\end{array}$} & \multirow[t]{2}{*}{$\begin{array}{c}\text { The } \\
\text { average } \\
\text { (T) }\end{array}$} & \multirow{2}{*}{$\begin{array}{l}\text { The value of } \\
\text { (T) the } \\
\text { calculated }\end{array}$} & \multirow{2}{*}{$\begin{array}{c}\text { The } \\
\text { functional } \\
\text { level }\end{array}$} \\
\hline & $\mathbf{M}$ & $\mathbf{P}$ & M & $\mathbf{P}$ & & & \\
\hline $\begin{array}{l}\text { Emotional } \\
\text { intelligence }\end{array}$ & 184.66 & 7.23 & 189.34 & 8.34 & 4.68 & 3.69 & Functional \\
\hline $\begin{array}{c}\text { Ability of } \\
\text { making a } \\
\text { decision }\end{array}$ & 187.43 & 9.63 & 164.58 & 7.78 & 22.85 & 32.18 & functional \\
\hline
\end{tabular}

The tabular value $(T)$ at the level $(0.05)=1.59$

From the previous table (13) we find out that there are statistical functional differences between moles and females from the scholastic administrative leaderships concerning emotional intelligence and the ability of taking the decision

\section{Second: Discussing the Results and Interpreting Them:}

The results of table (9) refers to the existing of a statistical functional correlation relationship between the emotional intelligence and the ability of making a decision, and this goes with what "Kharnop" (2003) said, that the emotional intelligence is a group of mental abilities, and comes from the completeness of the informative system and the emotional system that the emotional system is reasoning about the emotions, while the informative system is enhancing the informative ability, this can be explained as the emotional intelligence skills have a high degree of interesting and practicing with the scholastic administrative leaderships to develop such kind of intelligence, "Golman" (1998) maintained that the highness of emotional intelligence level doesn't mean that the individual has perfected the emotional skills, but it means that he has the extreme power to learn these skills, and as an example, the individual has the ability to empathy with others, but he doesn't learn the skill of empathy, which take the form of good treatment with others, and without learning the emotional skill he won't be able to fulfill any thing although he has the required emotional intelligence, "Golman" also Saw that to reach success, you should start with the mental ability, but it's not enough to fulfill the superiority and excellence, 
because there should be also the emotional qualification, to use it to the ultimate degree.

Also, the result of table (10) have pointed out to the existing of differences in the emotional intelligence between the scholastic administrative leaderships at Kenna and Zagazig governorates, the researchers see that due to the environment and its aspects like nature and its elements, components, phenomena, features, social aspect, habits, customs, values and the educational atmosphere of the so ciety in cluding the political administration and media administration because of its huge effect, and this goes with what "Ekbal Abd El Daim" (10) said, that the internal environment of the individual affected by what happens in the external environment directly, and this has its influences on the physiological and psychological aspects, and this reflects on the leadership behavior and his ability of making a decision. Also, "Alsamadony" (2001) confirmed what other studies refer to, that there are some emotional elements which are important in the personal success, and their role in the success is bigger than the role of the mental abilities.

Also, the results of table (11) have points out to the existing of statistical functional differences in the ability of making the decision to the scholastics administrative leaderships in Kenna and Zagazig, the researchers see that due to the difference of the environment, and what the environment supplies like information which contributes in makes the decision, also the researchers see that the differences due to the weakness of the possibilities and the lack of specialists staff to work at the modern compment, the absence of the modern administrative styles, the absence of the validity of making the decision, and doing the administrative and technique tasks that help reaching the quality, and not using the modern styles in training.

The results of table (12) have pointed out the absence of differences between those with high and low emotional intelligence concerning the ability of making the decision and this goes with what "Klard Wird" (2000) said, that the emotional intelligence level is used to evaluate the differences between individuals in planning, knowledge and collecting fields, and to clarify the differences between individuals in success in life, not as a qualitative measure intelligence for the traditional intelligence (1: 2005) and this goes with what "Diaa Aldeen Zahran" (1996) said, that making a decision, in its final analysis refers to a subjective and mental process to choose between two or more alternatives and this process depends mainly on the special skills of the decision maker $(7: 16)$

Also, the results of table (13) have pointed out to the exiting of differences between moles and females of the scholastic administrative leaderships concerning emotional intelligence and the ability of making a decision and this goes with the results of "Fawkia Rady's" study (2001), and Martha and George (2001), and this also doesn't go with the results of "Ghada Al Gendy's" study (2006) and "Sohad Al Melly" (2010). The researchers see that this results is due to the richness of the emotional life for those, who are more attention to their emotional lives, and this emotional sensitivity means that at any inducement, there will be passionate emotions whither negative or positive.

\section{Conclusions:}

In the light of the research, the researchers conclude the follow:

1. There is a statistical functional correlation coefficient between emotional intelligence and the ability of making a decision to the scholastic administrative leaderships.

2. There are statistical functional differences on the emotional intelligence between the scholastic administrative leaderships.

3. There are statistical functional differences on the ability of making the decision between males and females of the scholastic administrative leaderships.

4. There aren't statistical functional differences between those with high and low emotional intelligence at the ability of making a decision.

5. There are statistical functional differences between males and females of the scholastic administrative leaderships at emotional intelligence and the ability of making a decision. 


\section{Recommendations:}

In the light of this research, the researchers recommend the follow:

1. The necessity of practicing the scholastic administrative leaderships on participating making the decision.

2. The necessity of making a guided programs which aim at sharpen the emotional energies to the scholastic administrative leadership.

3. Put some roles that deal with some psychological and personal features and administrative skills to choose the scholastic administrative leaderships.

\section{References:}

\section{Arabic References:}

1. Alaa Mohammed Mubarak ( 2001 ): Educational Leadership secondary education in the light of contemporary trends " A Field Study, Master, Faculty of Education, Qena, South Valley University.

2. Diaa Elddin Zaher et al. ( 1996 ): " Calendar of school management in basic education " A field study of two provinces " , I 2, National Center for Examinations and Educational Evaluation, Cairo

3. Fawkiaa Mohamed Mohamed Radi (2001): " Emotional intelligence and its relationship to academic Achievement and the ability to creative thinking of students at the University ", Journal of the Faculty of Education, Mansoura University, No. (45) .

4. Feton Khrnop (2003): " Some cognitive styles and personality traits Alvariqhben people with high emotional intelligence and emotional intelligence have low high school students ", Unpublished Master Thesis, Institute of Educational Research and Studies, Cairo University .

5. Ghada Mathhar Elgeendy (2006) : " Differences in emotional intelligence among gifted students and demand E ordinary and their relationship to academic achievement " , Unpublished Master Thesis, Faculty of Educational Studies High, Amman Arab University for Graduate Studies, Amman .
6. Goleman Daniel (2000) " Emotional Intelligence " , A translation of the following is pregnant, a world of knowledge, Kuwait .

7. Ibrahim Abdullah Noori (1997): " The training needs of managers of primary schools and its impact on decision-making process ", Faculty of Education, An-Najah National University, Palestine .

8. Ibrahim Alsmaduny (2001 ): " Emotional intelligence and compatibility of the vocational teacher " A field study on a sample of the teachers secondary education, Journal of Education, the third issue .

9. Iqbal Abdel dayem, Muhammad old (1992) " Following components of the environment in different areas on some components of fitness and physiological variables " , Journal of Sport Sciences, Faculty of Physical Education, Minia University, Volume IV, No. IX, March .

10. Magdy Abdel Karim Habib ( 2001 ): Recent studies in the development of decisionmaking skills ", Journal of Psychology, No. Sixty, the Egyptian General Book Organization, Cairo 0

11. Mohamed Mahmoud Najib ( 2002 ): " Participation in decision-making and its relationship to both job satisfaction and face the setting and type of subordinate ", Journal of Psychology, The Egyptian General Book Organization, Cairo, number sixty-one .

12. Suhad Milli (2010): " Emotional intelligence and its relationship to academic Achievement among a sample of outstanding and ordinary ", A field study on the tenth grade students from schools and outstanding ordinary in the city of Damascus, Damascus University Journal vol. (26), The third issue.

\section{Foreign References:}

13. Armstrong, A. R., Galligan, R. F., \& Critchley, C. R. (2011): Emotional intelligence and psychological resilience to negative life events. Personality and Individual Differences, 51, 331-336.

14. Goleman,D (1995): Emotional intelligence. New York: Bantam Books.

15. Marttha, T.\& George, M.(2001): Emotional intelligence: the effect of gender, GPA, ethnicity. Paper presented at the Annual 
Meeting of the Mid- South Educational research Association. Mexico city, November.

16. Newsame, S. Day, A.L\& Catano, V.M (2000): Assessing the predictive validity of emotional intelligence. Personality and individual differences, .N29.

17. Parker, J.D(2004): Emotional intelligence and academic success: examining the transition from high school to university. Available online: ebsco host.htm.

18. Petrides, K. V., Pérez-GonzJlez, J. C., \& Furnham, A. (2007): On the criterion and incremental validity of trait emotional intelligence. Cognition and Emotion, 21, 26-55.
19. Stottlemyer, B.G. (2002): An examination of Emotional Intelligence: its relationship to achievement and implications for Education. Diss, abs, inter. Vol (63) N(2).

20. Shi, J., \& Wang, L. (2007): Validation of emotional intelligence scale in Chinese university students. Personality and Individual Differences, 43, 377-387

21. Woitaszewski, Scott, A \& Aalsma, Matthew, C.,(2004): The contribution of emotional intelligence to the social and academic success of gifted adolescents as measured by the Multifactor emotional intelligence. Scale- Adolescent version. Vol (27) (1). 